\title{
BIOLOGICAL REGENERATION OF LIQUID SORBENTS AFTER INDUSTRIAL PURIFICATION OF OUTLET GASES
}

\author{
Anna Trusek-Holownia*, Andrzej Noworyta \\ Wroclaw University of Technology, Department of Chemistry, Norwida 4/6, 50-33 Wrocław, \\ Poland
}

\begin{abstract}
Biological regeneration of water and organic sorbents used in the absorption of hydrophilic and hydrophobic pollutants, respectively, was studied. In both cases biodegradation takes place in a membrane bioreactor. In the case of organic sorbents regeneration of the biodegradation process is integrated with the extraction of a given pollutant to water phase. In experiments carried out in this work, the proposed systems were tested using a strain of Pseudomonas fluorescens. For hydrophilic compounds experiments were performed using alcohols (1-butanol and 2-propanol) as model substrates. Applying the mathematical model of a membrane bioreactor elaborated previously, the values of pollutant concentration were determined and positively verified in the experiments. This system of water sorbent regeneration is fully satisfying. The process of biodegradation integrated with extraction was analysed on the basis of model compounds such as benzene and toluene. The study confirmed a possibility of organic sorbent (silicone oil) regeneration. However, due to a very high partition coefficient of benzene or toluene between the organic and aqueous phases, the process could be considered only for the case of their high concentrations in the gas directed to absorption.
\end{abstract}

Keywords: biodegradation, membrane bioreactor, industrial gas purification, membrane contactor, VOC

\section{INTRODUCTION}

One of the classical methods to remove VOCs from industrial outlet gases is absorption, more often into hydrophobic than into hydrophilic solvents. In the case when a high concentration of a pollutant inside the sorbent is possible to achieve, the absorbate can be reused in the main technological process. When there is a mixture of sorbed pollutants, it is most reasonable to degrade them by catalytic burning or (bio)chemical degradation (Huang et al., 2005; Liao et al., 2008). Among these methods degradation carried out by microorganisms is characterised by the following features: 1) most compounds could be degraded to substances which are not hazardous for natural environment, usually to $\mathrm{CO}_{2}$ and $\mathrm{H}_{2} \mathrm{O}$; 2) a variety of microorganisms make it possible to select particular strain(s) or consortium of microorganisms capable of decomposition of given substance(s); 3) the cost of biodegradation is relatively low in comparison to other methods.

Due to the fact that the presence of water is essential for the subsistence of microorganisms there are two main strategies for biodegradation of compounds from industrial gases. The first one includes immobilisation of microorganisms on a solid surface in the form of a so-called "biofilm" through which a gas stream containing pollutants and a mineral nutrient stream pass in countercurrent (Hekmat et al., 2004; Pedersen and Arvin, 1997; Zhu et al., 1998). An important disadvantage of biofilm is the lack of complete control over the processes which occur simultaneously in it; particularly the biomass growth

*Corresponding author, e-mail: anna.trusek-holownia@pwr.wroc.pl 
of microorganisms depends on conditions in the column. An alternative to biofilm, which eliminates the disadvantages mentioned above, is equipment in which unit processes are controlled separately. At the first step, the mass of pollutant is transferred from industrial waste gas into liquid absorbent. Next, regeneration of the absorbent using microorganisms is carried in the bioreactor. During this process, the rate of biodegradation is usually very slow because it runs under substrate inhibition kinetics (Kim et al., 2005; Shim and Yang, 1999) which additionally limits the values of pollutant concentration in the bioreaction zone and consequently also the growth rate of bacteria and transformation of pollutants. These observations make biodegradation processes, although environment-friendly, not very attractive compared to chemical decomposition. A solution of this problem is to reduce residence time in the bioreactor by increasing the biomass concentration. This can be achieved by applying a microfiltration membrane which retains microorganism cells in the reaction zone that leads to the microbial membrane bioreactor.

In the previous study (Trusek-Holownia, 2008), a mathematical model was developed for a system consisting of a membrane module integrated with a stirred tank bioreactor - Fig. 1 .

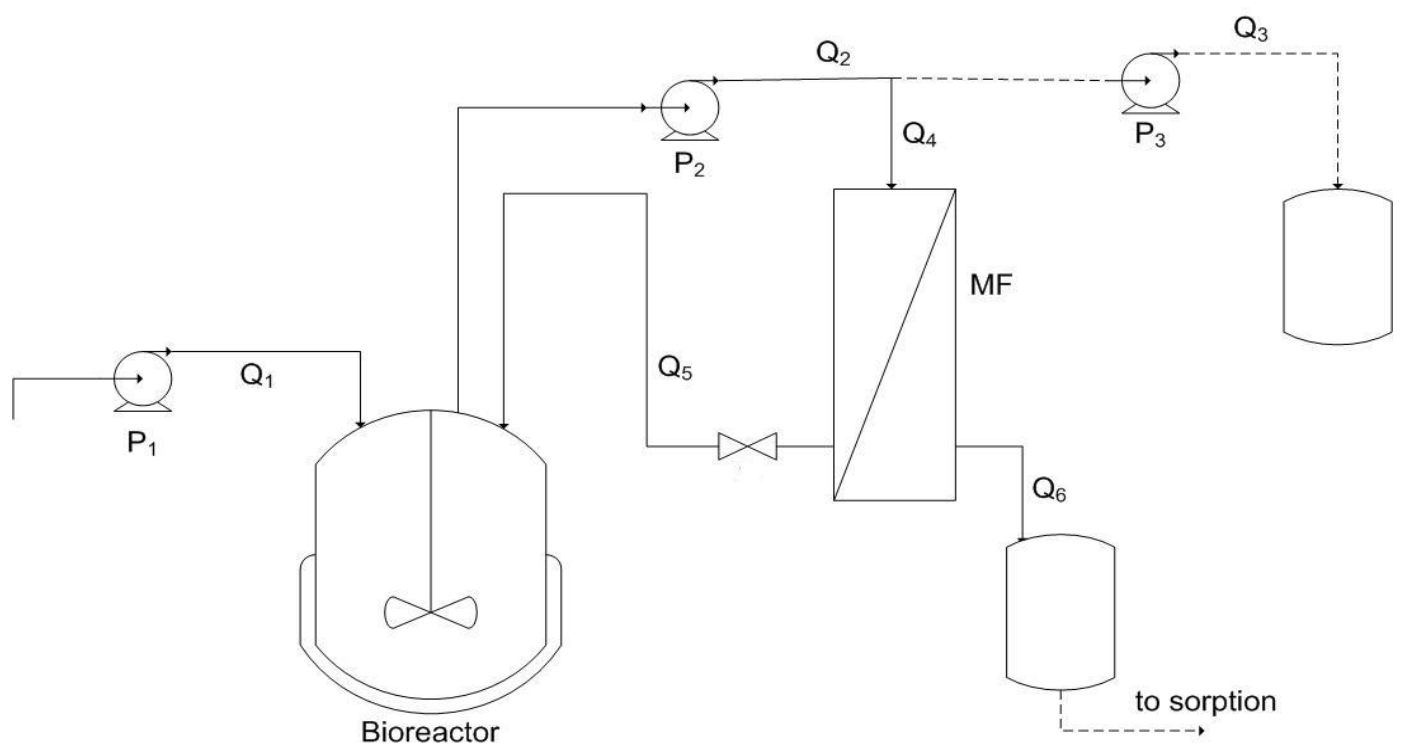

Fig. 1. Scheme of the set-up with a MF-membrane module

Stream from the bioreactor $\left(Q_{2}\right)$ is split into two streams: the stream of excess biomass $\left(Q_{3}\right)$ and the stream $\left(Q_{4}\right)$ directed to the membrane module. During membrane separation two streams are received: the retentate stream with concentrated biomass returned to the bioreactor and the permeate stream free of bacterial cells but containing mineral medium and substrates with a low molecular mass. At a high conversion degree of the substrate it can be reused in the absorption process.

Stream partition coefficient ( $\Psi$ ) was introduced to the model, where $Q_{1}$ is the dosing stream, $Q_{3}$ - stream of removal of biomass excess, $Q_{6}$ - permeate stream.

$$
\Psi=\frac{Q_{3}+Q_{6}}{Q_{3}}=\frac{Q_{1}}{Q_{3}}
$$

A domain of this coefficient is the range $(1, \infty)$, with the value of 1 corresponding to a classical continuously stirred tank reactor. The higher is this value, owing to the applied membrane, the higher is biomass concentration in the reactor in given conditions.

Assuming that membrane microfiltration completely rejects microbial cells and a change in cell concentration does not affect their physiology, the following formulas are obtained on the basis of the model: 


$$
\begin{gathered}
\tau_{M B}=\frac{1}{\mu \cdot \Psi}=\frac{\tau_{c l}}{\Psi} \\
X_{M B}=X_{c l} \cdot \Psi
\end{gathered}
$$

while the substrate concentration in the degradation zone is determined from the kinetic equation which determines the growth rate of the microbial cells.

$$
\mu=f\left(c_{s}\right)
$$

In the present study, the mentioned membrane bioreactor with a microfiltration module for regeneration of water sorbent including hydrophilic pollutant was applied.

Compounds characterised by high hydrophobicity could be removed effectively from polluted air streams by absorption into hydrophobic liquid (Khan and Ghosal, 2000; Munoz et al., 2006; Yeom et al., 2000). Regeneration of such an absorber is related to the extraction of biodegraded component to the aqueous phase where microorganisms are able to live. That is why in the second series of experiments this system was equipped additionally with a membrane contactor in which hydrophobic pollutant was extracted from the organic phase into water.

Each type of membrane bioreactors can be applied for a pure culture or for a consortium of microorganisms (as in the case of activated sludge). In the latter case, because of multiculturalism, the process is described with worse accuracy. To clearly show the benefits resulting from the application of membrane bioreactors, the presented experiments were performed using a single culture. The processes were carried out with VOCs often found in industrial gases and/or wastewater.

\section{MATERIALS AND METHODS}

\subsection{Microorganisms, culture broths}

A strain of Pseudomonas fluorescens PCM 2123 was purchased from the collection of IITD, Polish Academy of Sciences in Wroclaw (Poland). The culture medium was a broth consisting of $1 \mathrm{KNO}_{3}$, $1 \mathrm{KH}_{2} \mathrm{PO}_{4}, 1 \mathrm{~K}_{2} \mathrm{HPO}_{4}, 1 \mathrm{NaCl}, 0.02 \mathrm{CaCl}, 0.2 \mathrm{MgSO}_{4}$ and $0.001 \mathrm{FeCl}_{3}\left(\mathrm{~g} \mathrm{dm}^{-3}\right)$ at $p H$ 6.5.

Results of experiments carried out in the laboratory scale showed that Pseudomonas fluorescens was able to use $\mathrm{H}_{2} \mathrm{O}_{2}$ as an oxygen source and its concentration range of $0.005-0.03 \% \mathrm{v} / \mathrm{v}$ had no influence on the growth rate of the tested cultures. Thus, $\mathrm{H}_{2} \mathrm{O}_{2}$ was added to the bioreactor and to the dosing tank (in the case of continuous processes) at the concentration of $0.02 \% \mathrm{v} / \mathrm{v}$.

The use of $\mathrm{H}_{2} \mathrm{O}_{2}$ as a source of oxygen made it possible to carry out experiments in tightly closed tanks almost completely filled with the culture medium. This procedure excluded evaporation of degraded VOCs into the atmosphere.

The used strain was adapted for a month to the biodegradation of pollutants by increasing their concentration during subsequent charges. In the examined process the degraded substances were the only source of carbon and energy. Moreover, the medium did not contain organic nitrogen.

\subsection{Analytical methods}

The concentration of bacterial cells in the culture medium was monitored with a PharmaSpec UV-1700 spectrophotometer (Shimadzu, Japan) at the wavelength of $550 \mathrm{~nm}$. The equation derived on the basis of the dry mass method of $P$. fluorescens cells is Abs $(550)=2.5 \times\left(X\right.$ - biomass concentration, $\left.\mathrm{g} \cdot \mathrm{dm}^{-3}\right)$. 
The concentrations of substrates (degraded pollutants) were determined in a GC-2014 gas chromatograph (Shimadzu, Japan) with a ZB-WAXplus capillary column (Zebron) $30 \mathrm{~m}$ long and $0.25 \mathrm{~mm}$ in diameter, covered with a $0.25 \mu \mathrm{m}$ layer of polyethylene glycol. Samples taken from water were analysed after centrifugation of cells (4000 rpm, $15 \mathrm{~min}$.) in isothermal conditions in the column temperature of the column $40^{\circ} \mathrm{C}$ (for benzene, toluene) and $55^{\circ} \mathrm{C}$ (for alcohols), feeder $180^{\circ} \mathrm{C}$, detector $200^{\circ} \mathrm{C}$.

To determine benzene and toluene concentrations in the organic (absorbent) phase a $10 \mu \mathrm{l}$ sample taken from this phase was dissolved in $4.30 \mathrm{ml}$ of hexane and analysed by chromatography using the temperature gradient on the column ranging from 50 to $200^{\circ} \mathrm{C}$ (temperature of feeder $180^{\circ} \mathrm{C}$, detector $\left.200^{\circ} \mathrm{C}\right)$.

\subsection{Kinetic studies}

Preliminary experiments were performed in a batch system, using a single substrate. The initial substrate concentration was 0.12 to $4.6 \mathrm{~g} \mathrm{dm}^{-3}$ in the case of alcohols and 0.05 to $0.4 \mathrm{~g} \mathrm{dm}^{-3}$ for benzene or toluene. During the process the concentrations of biomass and substrate as described above were monitored.

In the continuous processes the alcohols were dosed at the concentration of $5 \mathrm{~g} \mathrm{dm}^{-3}$ and residence time ranging from 46 to $192 \mathrm{~h}$. In the case of benzene and toluene their concentration in dosing streams was $0.45 \mathrm{~g} \mathrm{dm}^{-3}$ and the residence time ranged from 80 to $162 \mathrm{~h}$.

All the experiments (batch and continuous processes) were carried out at a selected temperature $\left(30^{\circ} \mathrm{C}\right)$ in a 2.7 litre stirred reactor (New Brunswick BioFlo III, USA - Fig. 2) filled with 2.5 litre culture broth. All the media and equipment were sterilised in an autoclave at $121{ }^{\circ} \mathrm{C}$ before growing.
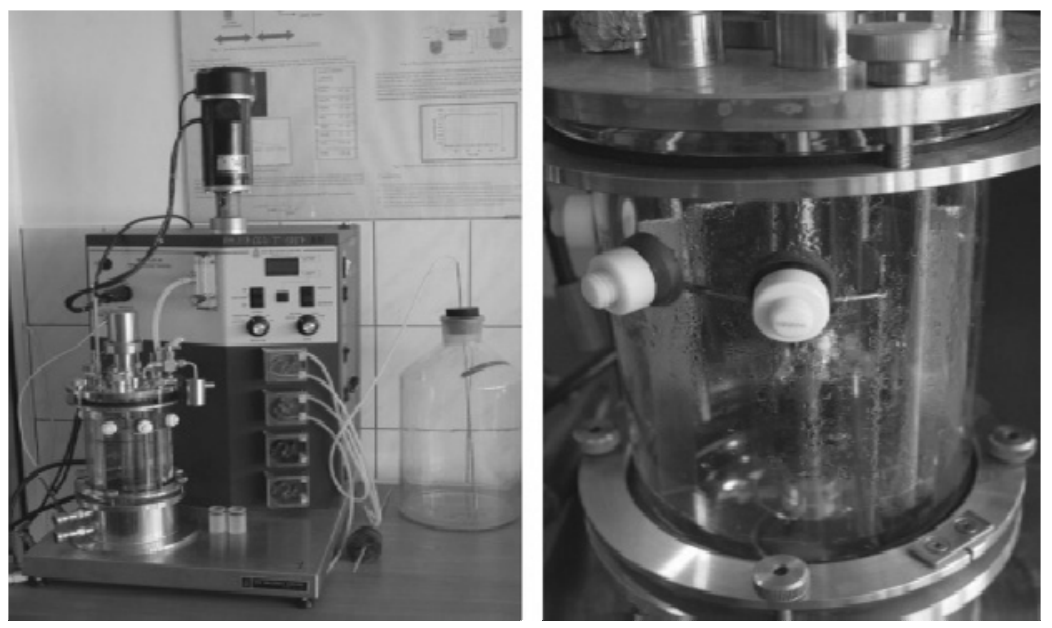

Fig. 2. New Brunswick BioFlo III reactor (USA)

\section{SCHEMES OF SYSTEMS WITH A BIOREACTOR INTEGRATED WITH MEMBRANE SEPARATION}

For hydrophilic compounds a system containing a microfiltration membrane module integrated with a stirred tank reactor shown in Fig. 1 was applied. The membrane module (IBIB, Warsaw, Poland) contained polysulphone capillary membranes $\left(d_{\text {pores }}=0.05 \mu \mathrm{m}, A=0.0126 \mathrm{~m}^{2}\right)$. It was sterilised with $90 \%$ ethyl alcohol for 1 hour. Selectivity of the membrane towards cells was determined by the retention coefficient (Eykamp, 1995; Mulder, 1996). 
For hydrophobic compounds, in the case when an organic solvent is applied as an absorbent, its regeneration integrated with biodegradation can be conducted in a periodic or continuous system presented in Fig. 3. A membrane module (IBIB, Warsaw, Poland) with polypropylene capillaries $\left(d_{\text {pores }}=0.1 \mu \mathrm{m}, A=0.0088 \mathrm{~m}^{2}\right.$ ) was used as a phase contactor. It was sterilised with $90 \%$ ethyl alcohol for 1 hour. This procedure also caused hydrophilisation of the polypropylene membranes. The organic phase at the volume of $1.5 \mathrm{dm}^{-3}$ was circulated on the shell side.

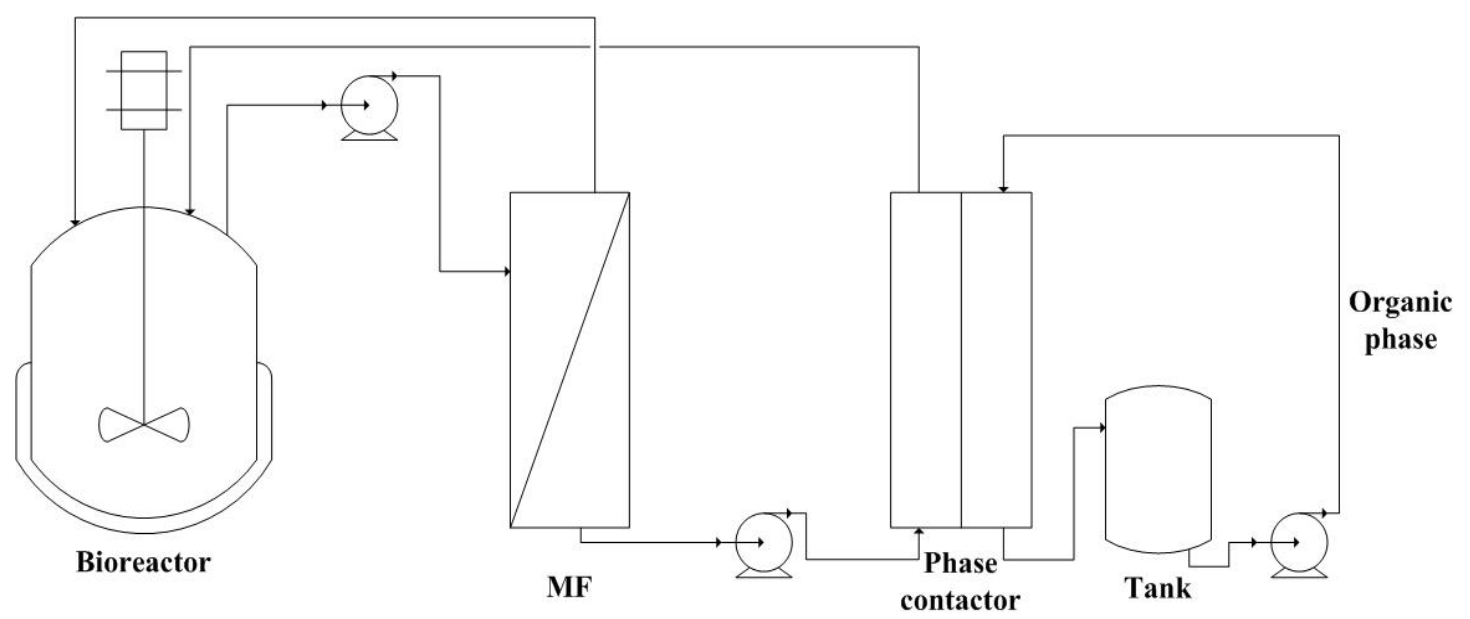

Fig. 3. Scheme of the set-up with a MF-membrane module and membrane phase contactor (an example of a periodic system)

Due to a significant difference in the rate of biodegradation (slow) and mass transport (fast due to an extensive interface area), it is recommended that the system should work as a periodic one. In this case, the stream leaving the stirred tank bioreactor is directed to the microfiltration module (MF), where microbial cells are separated and recirculated in the retentate stream to the bioreactor. The permeate from the MF module is directed to the membrane contactor where phases circulate in countercurrent. The capillaries and pores of the polypropylene membrane, which has been hydrophilized before the process, are filled with water phase (nutrient broth). In order to maintain interface in the membrane pores, slight overpressure $(0.15 \mathrm{MPa})$ is applied on the water phase side. After leaving the contactor, the aqueous phase enriched with a biodegraded component is introduced to the bioreactor, while the organic (absorbent) phase is circulated between the contactor and the tank filled with this phase.

\section{RESULTS}

\subsection{Regeneration of aqueous absorbents}

The simplest method to remove hydrophilic compounds from industrial gases is absorption in the water stream (clear in nutrient broth) directed immediately to the bioreactor. Experiments for this type of membrane bioreactors were carried out using alcohols (1-butanol and 2-propanol - the pollutants often present in industrial waste gases) as model substrates.

First of all, kinetic studies of biodegradation were performed in the batch system using a strain of $P$. fluorescens. The obtained results showed a strong substrate inhibition which for 2-propanol occurred already at the concentration of $2.8 \mathrm{~g} \mathrm{dm}^{-3}$, while for 1-butanol it appeared above $3.2 \mathrm{~g} \mathrm{dm}^{-3}$. Hence in the description of periodic processes, the equation (e.g. Haldane or Yamane) should take into account the part including this phenomenon (Saravanan et al., 2008; Zhuang et al., 2005).

Nevertheless, it is known that for the reaction with substrate inhibition steady state in the continuous process occurs only on the ascending arm of the kinetic curve (Tabis and Malik, 1998; Zhuang et al., 
2005). This fact was confirmed in our experiments carried out in the continuous systems. The experimental points obtained in this process could be described with high accuracy by the Monod equation (Monod, 1949). Table 1 presents determined constants of this equation which holds in the range of substrate concentrations below the inhibition level.

Table 1. Kinetics of biodegradation by $P$. fluorescens - constants of the Monod equation determined on the basis of points obtained in continuous processes

\begin{tabular}{|c|c|c|c|}
\hline & $\mu_{\max }\left[\mathrm{h}^{-1}\right]$ & $K_{S}\left[\mathrm{~g} \mathrm{dm}^{-3}\right]$ & $\begin{array}{c}\text { Range of applicability } \\
c_{S}\left[\mathrm{~g} \mathrm{dm}^{-3}\right]\end{array}$ \\
\hline 1-butanol & 0.074 & 7.50 & $<3.2$ \\
\hline 2-propanol & 0.048 & 6.92 & $<2.8$ \\
\hline
\end{tabular}

The concentration of a compound absorbed after regeneration (in stream $Q_{6}$ ) is important for sorbent regeneration process because it limits the driving force for sorption at the top of the column and thus affects the concentration in the outlet gas from the column. Henry's constant for the air-butanol-water system at $30^{\circ} \mathrm{C}$ is $0.525 \mathrm{~g} \mathrm{~m}^{-3}$ of air vs. $\mathrm{g} \mathrm{dm}^{-3}$ of water. In this study it was assumed that the concentration of 1-butanol in the gas would be equal to $0.2 \mathrm{~g} \mathrm{~m}^{-3}$, which is within the imposed standards. Thus, the balance in the gas-liquid system shows that its concentration in the regenerated absorbent (stream $Q_{6}$ ) should not exceed $0.4 \mathrm{~g} \mathrm{dm}^{-3}$.

Fig. 4 shows a correlation between residence time and the concentration of 1-butanol in the reactor for different values of parameter $\Psi$ which was calculated according to the mathematical model described in a previous study (Trusek-Holownia, 2008). Particularly, for a concentration of 1-butanol lower than 0.2 $\mathrm{g} \mathrm{dm}^{-3}$ there is a very strong dependence, and in this case choosing an appropriate value for the $\Psi$ coefficient is indispensable.

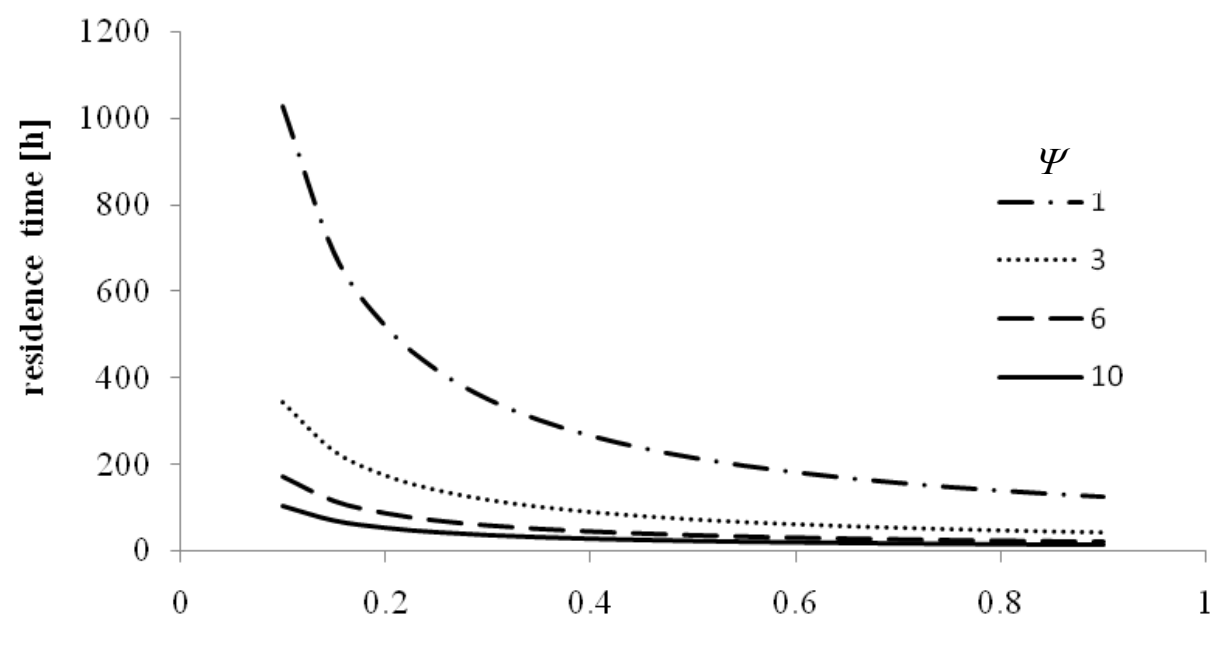

1-butanol concentration in bioreactor $\left[\mathrm{g} \mathrm{dm}^{-3}\right]$

Fig. 4. Dependence of the value of 1-butanol concentration and specified residence time in series at different values of $\Psi$

For a classical stirred bioreactor $(\Psi=1)$ a very long residence time is required and because of that using the biodegradation process is not really an attractive method. Nevertheless, as can be seen from Fig. 4, an application of a membrane bioreactor significantly reduces the reaction time, in accordance with Equation (2). 
Due to a relatively low mass stream of 1-butanol transferred to the liquid phase, the use of high values of coefficient $\Psi$ is not a problem. The correlation obtained theoretically was verified experimentally using a membrane bioreactor for the continuous process of 1-butanol degradation. The reactor operated in a stable way (Fig. 5). Experimental results (Table 2) fully correspond to the values obtained using the mathematical model.

Table 2. Verification of the process of 1-butanol biodegradation in membrane bioreactor

\begin{tabular}{|c|c|c|c|c|}
\hline $\begin{array}{c}\text { Concentration of } \\
1-\text { butanol in } Q_{1} \\
{\left[\mathrm{~g} \mathrm{dm}^{-3}\right]}\end{array}$ & $\begin{array}{c}\tau \\
{[\mathrm{h}]}\end{array}$ & $\Psi$ & \multicolumn{2}{|c|}{ Concentration of 1-butanol in $Q_{6}\left[\mathrm{~g} \mathrm{dm}^{-3}\right]$} \\
\hline & 24.5 & 8.22 & Model & Experimental (average) \\
\hline 1.5 & 30.3 & 7.82 & 0.54 & 0.51 \\
\hline 2.4 & 41.6 & 4.42 & 0.59 & 0.44 \\
\hline 3.5 & 55.4 & 3.97 & 0.49 & 0.61 \\
\hline 5.2 & & & 0.51 \\
\hline
\end{tabular}

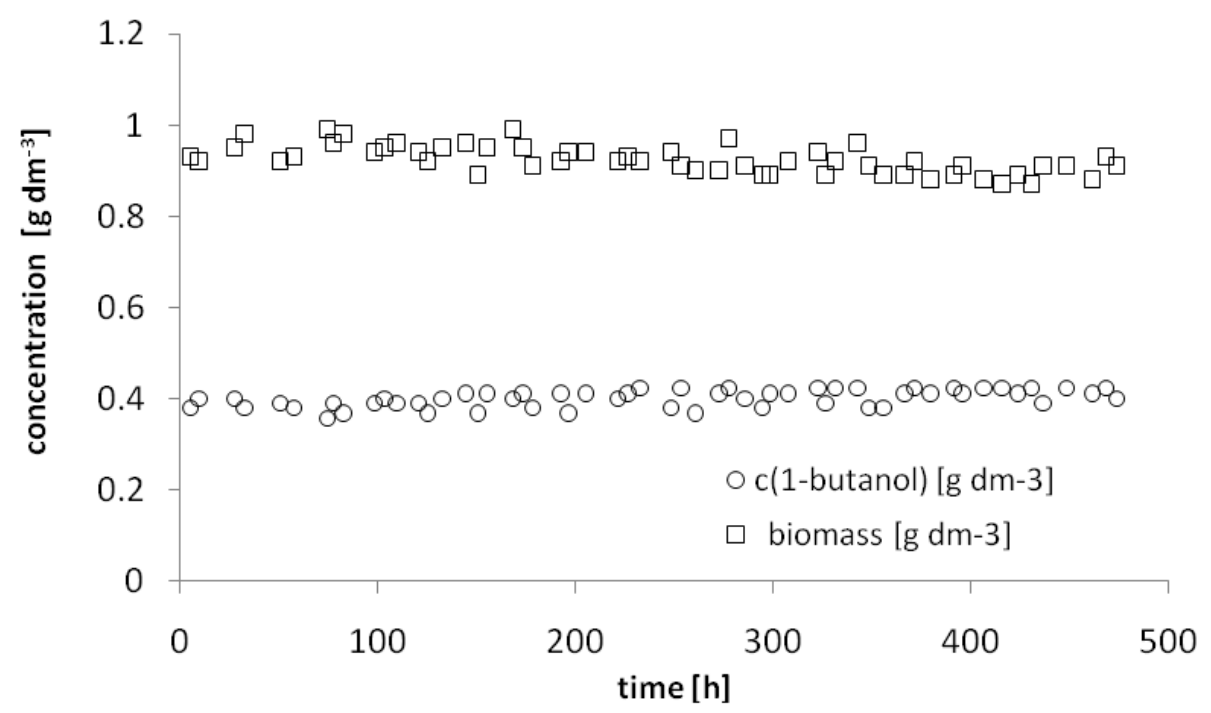

Fig. 5. An example of the process of biodegradation of 1-butanol in a membrane bioreactor. The 1-butanol concentration in stream $Q_{1}$ was $2.9 \mathrm{~g} \mathrm{dm}^{-3}, \tau=34.1 \mathrm{~h}, \Psi=7.82$. The expected (model) concentration of 1-butanol in the outlet stream $\left(Q_{6}\right)$ was $0.4 \mathrm{~g} \mathrm{dm}^{-3}$, the expected concentration of microbial cells in a bioreactor $0.925 \mathrm{~g} \mathrm{dm}^{-3}$ (based on the known value of $Y_{X / S}=0.37$ )

\subsection{Regeneration of hydrophobic absorbents}

A biodegradation process integrated with extraction was analysed on the basis of model compounds such as benzene and toluene degraded by $P$. fluorescens. Environmental standards for these compounds are very restrictive because of their highly carcinogenic nature.

Due to a very strong substrate inhibition which occurs during biodegradation, the substrate concentration range, where the process can be described by the Monod equation, is only to $0.15 \mathrm{~g} \mathrm{dm}^{-3}$. Kinetic constants determined on the basis of experimental points are presented in Table 3.

The choice of an organic solvent is significant for efficiency of both absorption and biodegradation processes. The organic phase is in permanent contact with the water phase so it cannot be toxic for the applied microorganisms and, simultaneously, cannot be biodegradable by them. For the bacterial strain 
tested in the present study, two solvents fulfil these requirements, i.e. 2,2,4,4,6,8,8-Heptanonane (HMN) and silicone oil. Simultaneously, the value of Henry's constant is important.

Table 3. Kinetics of biodegradation by P. fluorescens - constants in the Monod equation determined on the basis of points obtained in the batch homogeneous system

\begin{tabular}{|c|c|c|c|}
\hline & $\mu_{\max }\left[\mathrm{h}^{-1}\right]$ & $K_{S}\left[\mathrm{~g} \mathrm{dm}^{-3}\right]$ & $\begin{array}{c}\text { Range of applicability } \\
c_{S}\left[\mathrm{~g} \mathrm{dm}^{-3}\right]\end{array}$ \\
\hline Benzene & 0.008 & 0.011 & $<0.15$ \\
\hline Toluene & 0.021 & 0.119 & $<0.15$ \\
\hline
\end{tabular}

Henry's constant for the air-benzene-silicone oil system at $20^{\circ} \mathrm{C}$ is $1.2 \cdot 10^{-6} \mathrm{~g} \mathrm{~m}^{-3}$ of air vs. $\mathrm{g} \mathrm{m}^{-3}$ of silicone oil (Sander R., 1999). Thus, for example, the concentration of benzene in silicone oil is $80.0 \mathrm{~g}$ $\mathrm{dm}^{-3}$ and equilibrium concentration of the gas is $0.096 \mathrm{~g} \mathrm{~m}^{-3}$. This allows for the gas to be purified to the level of $0.10-0.12 \mathrm{~g} \mathrm{~m}^{-3}$ which means that the system may be important for benzene whose concentration in the gas exceeds $0.5 \mathrm{~g} \mathrm{~m}^{-3}$.

For both selected organic solvents extraction equilibrium was determined in optimal conditions for P. fluorescens growth $\left(30^{\circ} \mathrm{C}, \mathrm{pH} 6.5\right)$. For the tested compounds no dependence (benzene) or slight dependence (toluene) of the partition coefficient on the applied solvents was observed. Dependence of the extracted substance concentration on organic and water phase is shown in Fig. 6. This result is in agreement with literature data obtained for other extraction systems (Long et al., 2008; Spiess et al., 2008).
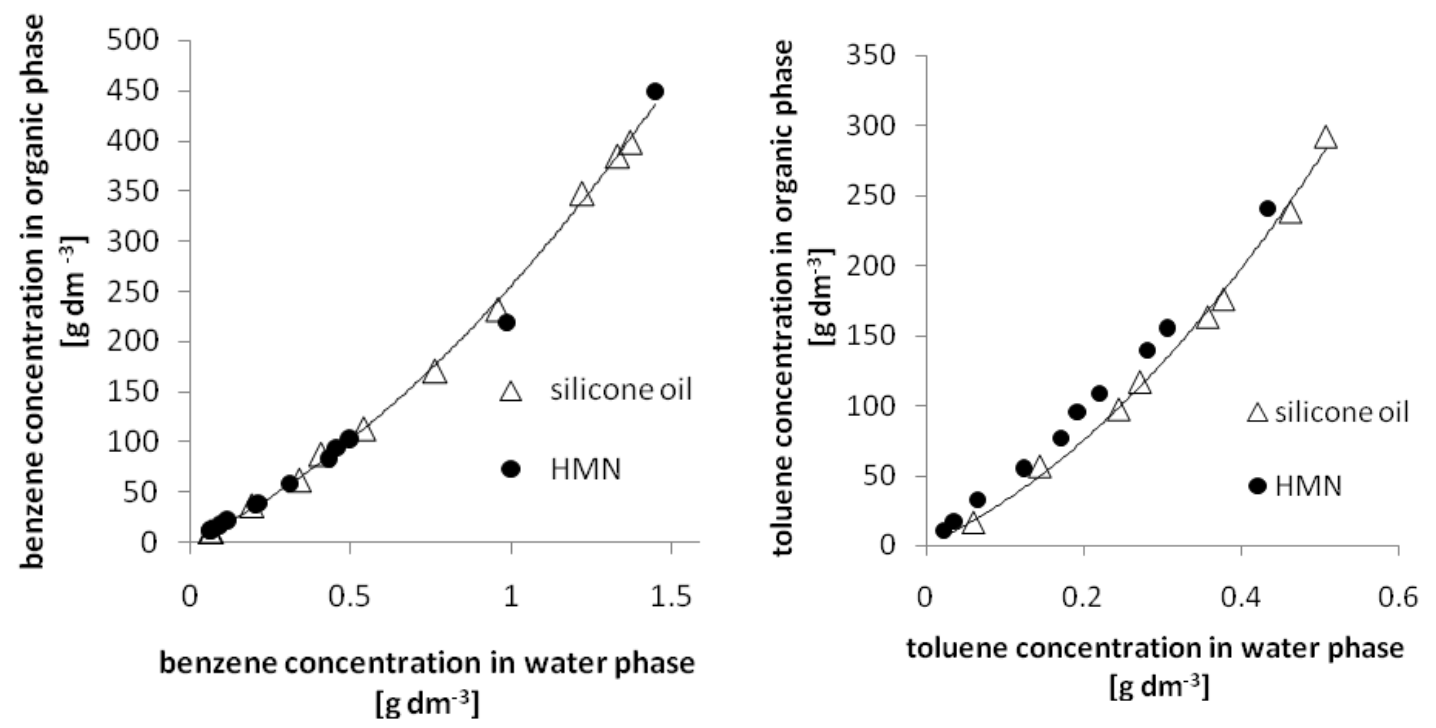

Fig. 6. Benzene (a) and toluene (b) extraction equilibrium in the system with silicone oil and with HMN $\left(30^{\circ} \mathrm{C}, \mathrm{pH} 6.5\right)$

A high value obtained for coefficient $\mathrm{P}$ is logical if hydrophobicity of the extracted components is analysed, but is not beneficial to the process of mass transfer from the organic phase to water. Therefore, to obtain the concentration of benzene or toluene at several hundred $\mathrm{mg} \mathrm{dm}^{-3}$ in the aqueous phase its concentration in the organic phase must be in the range of 30-100 $\mathrm{g} \mathrm{dm}^{-3}$. Such a high benzene concentration in the organic phase reduces the quantity of this compound in the gas obtained after purification, and thus the area of application of this type of solvents is limited.

The first attempts of organic phase regeneration were made in an emulsified system in the stirred bioreactor, as this is the simplest method. The organic phase was silicone oil which contained 5.59 to 
$50.15 \mathrm{~g} \mathrm{dm}^{-3}$ of benzene or 8.04 to $81.08 \mathrm{~g} \mathrm{dm}^{-3}$ of toluene in subsequent experiments. The water to organic phase ratio was 9.25:1. During the process, benzene/toluene concentration in both phases and cell concentration in the water phase was measured. Exemplary data are shown in Fig. 7. The rate of benzene biodegradation was about $0.01 \mathrm{~g} \mathrm{dm}^{-3} \mathrm{~h}^{-1}$, which is the value only slightly lower than that obtained for 1-butanol at low concentrations.

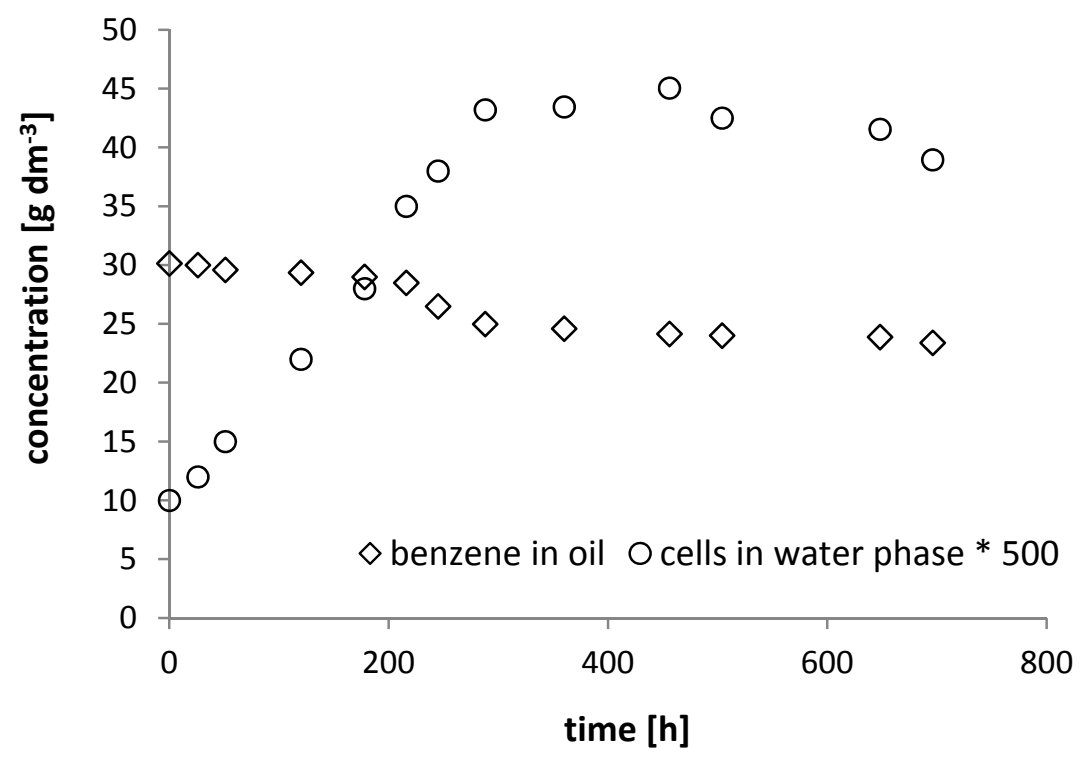

Fig. 7. An example of the processes of regeneration of the absorbent organic phase by Pseudomonas fluorescens in the emulsified system. The change of cell concentration in the reactor (multiplied 500 times) and the concentration of benzene in silicone oil (initial benzene concentration in silicone oil $=30.0 \mathrm{~g} \mathrm{dm}^{-3}$, initial concentration of cells $0.05 \mathrm{~g} \mathrm{dm}^{-3}$ )

After ca. 220-248 h, irrespective of the kind of substrate (benzene or toluene) and its initial concentration, a compacting of cells and formation of floccules located near the phase interface was observed. Single cells were visible also in the oil phase. In the experiments where silicone oil contained higher concentrations of benzene $\left(>35 \mathrm{~g} \mathrm{dm}^{-3}\right)$, or toluene $\left(>42 \mathrm{~g} \mathrm{dm}^{-3}\right)$ no cell growth was observed, which provided the evidence of a strong inhibiting effect of benzene and toluene caused by their contact with microorganisms at the interface. These results showed that a heterogeneous bioreactor was inadequate for the examined process.

An alternative to organic absorbent regeneration is a system shown in Fig. 3. This is a typical hybrid process which concerns a microbial membrane bioreactor integrated with a membrane contactor working as an extractor. Such a device was built in a laboratory scale and tested to verify the proposed method. Due to very large differences in the concentrations observed in the organic and aqueous phases, similar differences were reported in the flow of both phases. For this reason it was decided to conduct the process in the pseudostationary state. Although in this case, the organic phase circulated in a closed circuit, concentration changes during the experiment were so small that the concentration could be assumed as a constant (average) value. An example of the correlation between benzene concentration in both phases is shown in Fig. 8.

The study confirmed the possibility of organic sorbent regeneration. However, due to a very high partition coefficient of benzene between the organic and aqueous phases, the process can be considered only for the cases of high concentrations of benzene in the gas directed to absorption. 


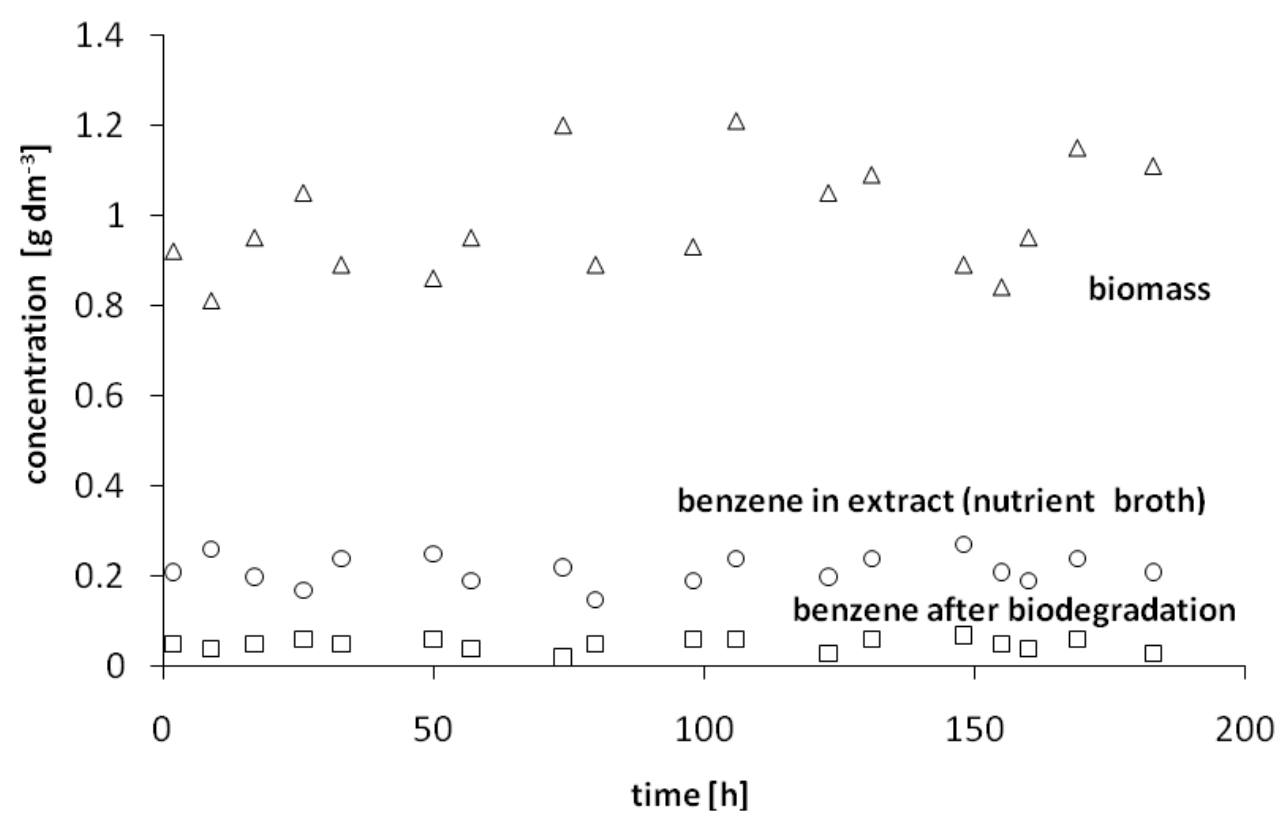

Fig. 8. An example of the processes of regeneration of the absorbent organic phase by P. fluorescens in the integrated system (organic phase stream $0.083 \mathrm{dm}^{3} \mathrm{~h}^{-1}$, water phase (nutrient broth) stream $0.29 \mathrm{dm}^{3} \mathrm{~h}^{-1}$, the concentration of benzene in silicone oil $64.5 \mathrm{~g} \mathrm{dm}^{-3}$, the expected concentration of benzene after biodegradation $0.04 \mathrm{~g} \mathrm{dm}^{-3}$ )

\section{CONCLUSIONS}

Regeneration of the two types of gas pollutants; hydrophilic and hydrophobic, was considered. In the case of hydrophilic substances an aqueous solution containing broth with mineral components can be used as a sorbent, which can further be bioregenerated in an efficient way. Due to a relatively low concentration of biodegraded substance in the solution it is preferable to use a membrane bioreactor. Because of a rather strong dependence of Henry's constant on the temperature in the selection of process parameters for integrated biodegradation and absorption processes, it is recommended to optimise them in view of temperature.

In the case of hydrophobic pollutants an organic solvent should be used as a sorbent. Direct regeneration of such a solvent in an emulsion bioreactor is not effective in long processes because of strong cell adhesion to the interface. A solution is to apply an effective extraction (e.g. in a membrane contactor). Depending on the equilibriums of gas-organic solvent-water solutions, the proposed process is limited to the systems where high concentrations of pollutants occur in the exhaust gases.

This work was supported in a framework of a project 344069/Z0311.

\section{SYMBOLS}

$c_{S} \quad$ substrate concentration, $\mathrm{g} \mathrm{dm}^{-3}$

$c^{*} \quad$ equilibrium concentration, $\mathrm{g} \mathrm{dm}^{-3}$

$K_{S} \quad$ Monod constant, $\mathrm{g} \mathrm{dm}^{-3}$

$P \quad$ equilibrium partition coefficient; $\mathrm{P}_{\mathrm{i}}=\mathrm{c}^{*}{ }_{\mathrm{i}, \text { org }} / \mathrm{c}^{*}{ }_{\mathrm{i}, \text { aq }}$

$Q \quad$ stream, $\mathrm{dm}^{3} \mathrm{~h}^{-1}$

$X \quad$ biomass concentration, $\mathrm{g} \mathrm{dm}^{-3}$ 
$Y_{X / S} \quad$ biomass yield coefficient, $\mathrm{g}_{\mathrm{X}} \mathrm{g}_{\mathrm{S}}{ }^{-1}$

$\begin{array}{ll}\text { Greek symbols } \\ \mu & \text { specific growth rate, } \mathrm{h}^{-1} \\ \mu_{\max } & \text { maximal specific growth rate, } \mathrm{h}^{-1} \\ \tau & \text { hydraulic residence time, } \mathrm{h} \\ \Psi & \text { streams division coefficient (Eq. (1)) } \\ & \\ \text { Subscripts } & \\ \text { aq } & \text { aqueous phase } \\ \text { cl } & \text { classical bioreactor } \\ M B & \text { membrane bioreactor } \\ \text { org } & \text { organic phase }\end{array}$

\section{REFERENCES}

Eykamp W., 1995. Microfiltration and ultrafiltration, In: Noble R.D., Stern S.A. (Eds.), Membrane science and technology series, Vol. 2, Membrane separations technology. Principles and applications. Elsevier, Amsterdam, The Netherlands.

Hekmat D., Feuchtinger A., Stephan M., Vortmeyer D., 2004. Biofilm population dynamics in a trickle - bed bioreactor used for the biodegradation of aromatic hydrocarbons from waste gas under transient conditions. Biodegradation, 15, 2, 133-144. DOI: 10.1023/B:BIOD.0000015647.21321.df.

Huang K.-Ch., Zhao Z., Hoag G.E., Dahmani A., Block P.A., 2005. Degradation of volatile organic compounds with thermally activated persulfate oxidation. Chemosphere, 61, 4, 551-560. DOI: 10.1016/j.chemosphere.2005.02.032.

Khan F.I., Ghosal A.K., 2000. Removal of volative organic compounds from polluted air. J. Loss Prevent. Process Industr., 13, 527-545. DOI: 10.1016/S0950-4230(00)00007-3.

Kim D-J., Choi J-W., Choi N-C., Mahendran B., Lee C-E., 2005. Modeling of growth kinetics for Pseudomonas spp. during benzene degradation. Appl. Microbiol. Biotechnol., 69, 4, 456-462. DOI: 10.1007/s00253-0051997-z.

Liao Q., Tian X., Zhu X., Chen R., Wang Y.Z., 2008. Measurements and modeling of heat generation in a trickling biofilter for biodegradation of a low concentration volatile organic compound (VOC). Chem. Eng. J., 140, 221-234. DOI: 10.1016/j.cej.2007.09.043.

Long B., Wang Y., Yang Z., 2008. Partition behavior of benzoic acid in (water $+n$-dodecane) solutions at $T=$ (293.15 and 298.15). J. Chem. Thermodyn., 40, 1565 - 1568. DOI: 10.1016/j.jct.2008.06.014.

Monod J., 1949. The growth of bacterial cultures. Ann. Rev. Microbiol., 3, 371-393. DOI: 10.1146/annurev.mi.03.100149.002103.

Mulder M., 1996. Basic principles of membrane technology. Kluwer Academic Publishers, Dordrecht, The Netherlands.

Muñoz R., Arriaga S., Hernández S., Guieysse B., Revah S., 2006. Enhanced hexane biodegradation in a two phase partitioning bioreactor: Overcoming pollutant transport limitations. Process Biochem., 41, 1614-1619. DOI: 10.1016/j.procbio.2006.03.007.

Pedersen A.R., Arvin E., 1997. Toluene removal in a biofilm reactor for waste gas treatment. Water Sci. Technol., 36, 1, 69-76. DOI: 10.1016/S0273-1223(97)00324-7.

Sander R., 1999. Compilation of Henry's law constants for inorganic and organic species of potential importance in environmental chemistry. Retrieved from http://www.henrys-law.org.

Saravanan P., Pakshirajan K., Saha P., 2008. Growth kinetics of an indigenous mixed microbial consortium during phenol degradation in a batch reactor. Bioresource Technol., 99, 1, 205-209. DOI: 10.1016/j.biortech.2006.11.045. 
Shim H., Yang S.-T., 1999. Biodegradation of benzene, toluene, ethylbenzene and o-xylene by coculture of Pseudomonas putida and Pseudomonas fluorescens immobilized in a fibrous-bed bioreactor. J. Biotechnol., 67, 99-112. DOI: 10.1016/S0168-1656(98)00166-7.

Spieß A.C., Eberhard W., Peters M., Eckstein M.F., Greiner L., Büchs J., 2008. Prediction of partitions coefficients using COSMO-RS: Solvent screening for maximum conversion in biocatalytic two-phase reaction systems. Chem. Eng. Proc., 47, 1034-1041. DOI: 10.1016/j.cep.2007.02.007.

Tabiś B., Malik J., 1998. Stability characteristics of a biochemical reactor with predator - prey relationship. A substrate inhibition case. Chem. Eng. J., 70, 3, 179-188. DOI: 10.1016/S1385-8947(98)00094-1.

Trusek-Holownia A., 2008. Wastewater treatment in a microbial membrane bioreactor - a model of a process. Desalination, 221, 552-558. DOI: 10.1016/j.desal.2007.01.116.

Yeom S.-H., Dalm M.C.F., Daugulis A.J., 2000. Treatment of high-concentration gaseous benzene streams using a novel bioreactor system. Biotechnol. Lett., 22, 1747-1751. DOI: 10.1023/A:1005689917744.

Zhu X., Alonso C., Suidan M.T., Cao H., Kim B.J., Kim R.R., 1998. The effect of liquid phase on VOC removal in trickle-bed biofilters. Water Sci. Technol., 38, 3, 315-322 . DOI: 10.1016/S0273-1223(98)00557-5.

Zhuang W.-Q., Tay J.-H., Yi S., Tay S.T.-L., 2005. Microbial adaptation to biodegradation of tert-butyl alcohol in a sequencing batch reactor. J. Biotechnol., 118, 1, 45-53. DOI: 10.1016/j.jbiotec.2005.02.014.

Received 04 June 2012

Received in revised form 18 November 2012

Accepted 21 November 2012 